\title{
Comparative Studies on Two Fluoro-Substituted 2-Pyrazoline Derivatives with Experimental and Theoretical Methods
}

\author{
Huan Mei Guo, ${ }^{+}$Xian Wang, ${ }^{\ddagger}$ Fang Fang Jian, ${ }^{,+}$Hai Lian Xiao, ${ }^{\ddagger}$ and Pu Su Zha $0^{\ddagger *}$ \\ ti ficroscale Science Institute, Weifang College, Heifang Shandong 261061, P. R. China

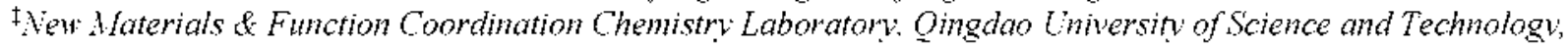 \\ Qingdao Shandong 2660+2, P. R. China. "E-mail: zhaopusutal63.com \\ Received February 2, 2008, Accepted March 17, 2009
}

\begin{abstract}
Two fluoro-substituted 2-pyrazoline derivatives, 1-pheny 1-3-(4-methoxyphenyl)-5-(4-fluorophenyl)-2-pyrazoline (1) and 1-phenyl-3-(4-methoxypheny1)-5-(2-fluoro-phenyl)-2-pyrazoline (2) have been synthesized and characterized by elemental analysis, IR, UV-Vis and fluorescence spectra. The crystal structure of $\mathbf{1}$ has been determined by X-ray single crystal diffraction. For the two compounds, density functional theory (DFT) calculations of the structures and natural population atomic charge analy sis (NPA) have been performed at B3L YP/6-3 $116^{* *}$ level of theory. By using TD-DFT method, electron spectra of $\mathbf{1}$ and $\mathbf{2}$ have been predicted, which are very approximate with the experimental ones. Comparative studies on 1 and 2 indicate that the location change of fluorine atom in 5-position phenyl ring of 2-pyrazoline does not make significant change of geometries and electronic transition bands, but it leads to evident change of atomic charge distributions and peak intensities of UV and fluorescence spectra.
\end{abstract}

Key Wonds: Crystal structure, DFT calculation. Atomic charge distribution. Electronic spectra. Fluorescence spectra

\section{Intoduction}

The organic electroluminescence (OEL) devices have shown several advantages over inorganic ones, such as low cost. high luminous efficiency, wide selection of emission colors and easy processing. Recently, a lot of works have been focused on blue color emitting materials. ${ }^{1-3}$ Pỵrazoline derivatives. as fine blue light emission materials with high quantum yield. $^{4 \cdot 7}$ have been investigated in many respects. Many 1,3.5triaryl-2-py razolines have been reported as hole transporting or emitting materials in organic EL devices. ${ }^{8.11}$ Our group recently have also focused our attentions on investigating 1,3,5-triaryl-2-pyrazolines. ${ }^{1-16}$ However, till now. comparative studies on 1.3.5-triaryl-2-pyrazolines by both experimental and theoretical methods are relatively rare. Herein. we wish to report the synthesis. characterization and calculational studies on two fluoro-substituted 2-py razoline derivatives. 1-pheny'l3-(4-methoxyphenyl)-5-(4-fluoropheny l)-2-pyrazoline (1) and 1-phenyl-3-(4-methoxy phenyl)-5-(2-fluo rophenyl)-2pyrazoline (2). including the crystal structure of 1. Also. by using experimental and theoretical methods, some comparisons have been made between the two compounds. since the electron-w ithdrawing group of fluorine atom is located at two different positions in 1 and 2 . We hope the comparisons can indicate the effect of the substituent on the electronic structure. which will provide insights that would be valuable to the ongoing research on electroluminescent device and could guide the molecular design of pyrazoline-based electroluminescent materials.

\section{Experimental and Theoretical Methods}

Physical measurements. Elemental analyses for carbon. hydrogen and nitrogen were performed by a Perkin-Elmer 240C elemental instrument. Electronic absorption spectra were measured on a Shimadzu UV3 100 spectrophotometer in EtOH solution and solid-state fluorescence spectra were measured on a F96-fluorospectrophotometer.

Synthesis. All chemicals were obtained front a commercial source and used without further purification.

Synthesis of 1-phenyl-3-(t-methoxyphenyl)-5-(t-fluorophenyl)- 2-pyrazoline (1): 1-(4-Methoxyphenyl)-3-(4-fluorophenyl)-2-propenyl-1-ketone ( $0.01 \mathrm{~mol}$ ) and phenyllyy drazine $(0.015 \mathrm{~mol})$ were mixed in acetic acid $(40 \mathrm{~mL})$ and stirred during refluxing for $6 \mathrm{~h}$. Then, the mixture was poured into ice-water to afford yellow solids. The solids were filtrated and washed with water until $\mathrm{pH}$ of the solution is about 7 . Finally. the yellow solid cry stals of 1 were dried at room temperature. Yield $88 \%$. m.p. $134-135{ }^{\circ} \mathrm{C}$. Anal. Calcd. for $\mathrm{C}_{2} \mathrm{H}_{1} \circ \mathrm{FN}_{2} \mathrm{O}$ : C. 76.28: H, 5.53: N. 8.09. Found: C. 76.09: H. 5.43: N. 8.00. IR: $v 3440$ (s). 1599 (s). 1499 (s). 1383 (n). 1246 (n). 1030 (m). $827(\mathrm{~m}) .741$ (m). $534(\mathrm{~m}) \mathrm{cm}^{-1}$. The single crystals suitable for $\mathrm{X}$-ray measurements were obtained by recrystallization from acetic ether at room temperature.

Synthesis of 1-phenyl-3-(4-methcxylphneyl)-5-(2-fluorophenyl)-2-pyrazoline (2): In order to obtain 2 . the same procedure as for 1 was used. 1-(4-Methoxylphenyl)-3-(2-fluorophenyl)-2-propenyl-1-ketone (0.01 mol) was used in place of 1-(4-methoxy phenyl)-3-(4-fluo rophenyl)-2-propeny l- Iketone $(0.01 \mathrm{~mol})$. Yield 82\%. m.p. 139.5-140.2 'C. Anal. Calcd for $\mathrm{C}_{2} \mathrm{H}_{1}, \mathrm{FN}_{2} \mathrm{O}$ : C, 76.28; H. 5.53; N. 8.09. Found: $\mathrm{C}$, 76.09: H. 5.43: N. 8.00. RR: 3448 (s). 1590 (s). 1499 (s). 1383 (m). 1254 (m), 1014 (n), 831 (m). 741 (m). $690(\mathrm{nl}) \mathrm{cm}^{-1}$.

Crystal structure detemination of 1 . The selected light yellow crystal of 1 was mounted on a CCD area diffractometer. Reflection data were measured at $0^{\circ} \mathrm{C}$ using graplite 
monochromated Mo-Ka $(\lambda=0.71073 \mathrm{~A})$ radiation and a $\varphi-\omega)$ scan mode. The structure was solved by direct methods and refined by full-matrix least-squares method on $F_{\text {obs }}{ }^{2}$ using the SHELXTL software package. All non-H atoms were anisotropically refined. The hydrogen atom positions were fixed geometrically at calculated distances and allowed to ride on the parent $\mathrm{C}$ atoms. Atomic scattering factors and anomalous dispersion corrections were taken from International Table for X-ray Crystallography. ${ }^{18}$

Computational methods. Initial molecular geometries were optimized using MM+ molecular modeling and semi-empirical AMl methods ${ }^{1.5}$ (HYPERCHEM 6.0. Hypercube. Ont.. Canada). Then, DFT calculations with a hybrid functional B3LYP at basis set 6-311G** by the Berny method ${ }^{\text {(1) }}$ were performed with the Gaussian 03 software package. ${ }^{21}$ The calculated vibrational frequencies ascertained that the structures were stable (no imaginary frequencies). Based on the optimized geometries and by using time-dependent density functional theory (TD-DFT) ${ }^{-2-4}$ methods. electronic spectra of 1 and 2 were predicted, respectively. Natural Bond Orbital $(\mathrm{NBO})^{35}$ analyses were also performed based on the optimized geometries.

All calculations were performed on a DELL PE 2850 server and a Pentium IV computer using the default convergence criteria

\section{Results and Discussion}

Crystal structure of 1 . The compound 1 crystallizes in triclinic system. space group $P-1$, with lattice parameters $a=$ $9.443(7) \AA . b=10.210(7) \AA . c=19.626(13) \AA . \alpha=91.445$ $(13)^{\circ} . \beta=101.873(14)^{\circ}, \gamma=92.688(14)^{\circ} . \mathrm{I}^{\circ}=1849(2) \mathrm{A}^{3} . \mathrm{M} / \mathrm{r}=$ $692.78\left(\mathrm{C}_{44} \mathrm{H}_{38} \mathrm{~F}_{2} \mathrm{~N}_{4} \mathrm{O}_{2}\right) . Z=2, D_{\mathcal{C}}=1.245 \mathrm{~g} / \mathrm{cm}^{3} . \mu=0.084$ $\mathrm{mm}^{-1}, F(000)=728 . R=0.0946, w R_{2}=0.2146$. A displacement ellipsoid plot. with the numbering scheme, is shown in Figure 1.

The structure of 1 contains two independent $\left[\mathrm{CH}_{3} \mathrm{OPhC}_{3}\right.$ -
$\mathrm{H}_{3} \mathrm{~N}_{2} \mathrm{PhPhF}$ ] structural units, hereafter named Sl [containing $\mathrm{F}(\mathrm{I})$ atom] and S2 [containing F(2) atom]. Selected bond lengths and bond angles by $\mathrm{X}$-ray diffraction are listed in Table 1 . All of the bond lengths and bond angles in phenyl rings are in the normal range. In pyrazolinyl rings, the bond lengths of $\mathrm{C}=\mathrm{N}$ and $\mathrm{C}-\mathrm{N}$ are shorter than those found in similar structures $[\mathrm{C}=\mathrm{N} 1.29 \mathrm{l}(2)-1.300(10) \mathrm{A} . \mathrm{C}-\mathrm{N} 1.482(2)$ $1.515(9) \AA]$, while both the $\mathrm{N}-\mathrm{N}$ bond length are longer than those found in the above-cited structures $[N-N$ 1.373(2)$1.380(8) \AA]{ }^{26}$ The bond angles in the two py razolimyl rings are all in good agreement with those in the above cited structures ${ }^{-5}$ The dihedral angles between the pyrazolinyl ring with the phenyl rings at positions 1,3 and 5 of the pyrazoline are $17.8(3)^{\circ} .15 .8(3)^{\circ}$ and $79.0(2)^{\circ}$ in $\mathrm{Sl}$ and $15.1(3)^{\circ}, 13.0(3)^{\circ}$ and $78.3(3)^{\circ}$ in $\$ 2$, respectively

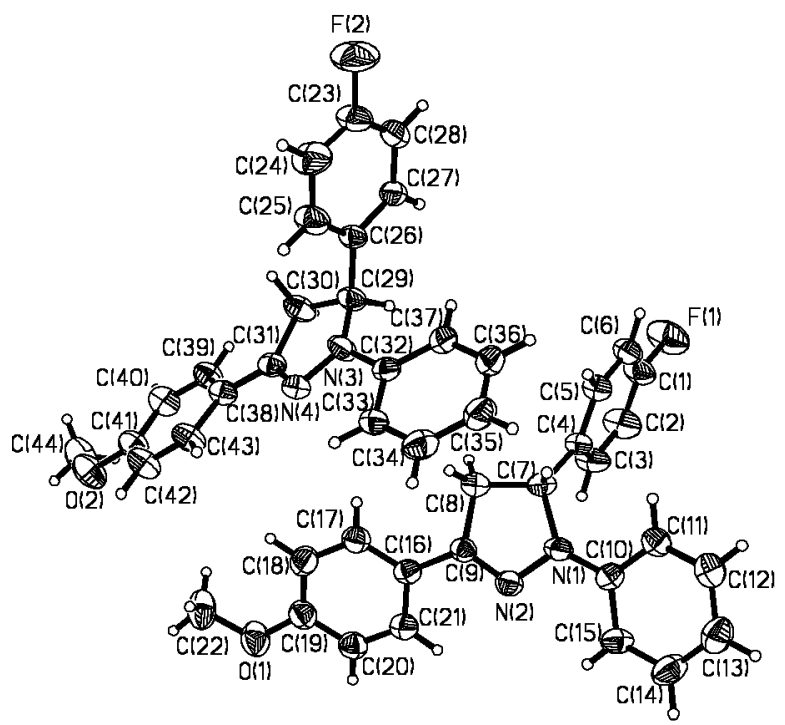

Figure 1. The molecular structure with the atomic numbering for the compound 1.

Table 1. Selected geometric parameters by X-ray for 1 and theoretical calculations for 1 and 2 at B3LYP/6-31 $1 G^{* *}$ level of theory.

\begin{tabular}{|c|c|c|c|c|c|}
\hline Bond lengths $(\AA)$ & Exp.for 1 & Bond lengths & Exp.for 1 & Calc for 1 & Calc. for 2 \\
\hline$N(1)-N(2)$ & $1.390(5)$ & $N(3)-N(4)$ & $1.385(5)$ & 1.370 & 1.366 \\
\hline$N(2)=C(9)$ & $1.275(5)$ & $N(4)=C(31)$ & $1.280(5)$ & 1.288 & 1.286 \\
\hline $\mathrm{N}(1)-\mathrm{C}(7)$ & $1.480(5)$ & $N(3)-C(29)$ & $1.472(6)$ & 1.479 & 1.482 \\
\hline $\mathrm{C}(1)-\mathrm{C}(2)$ & $1.369(7)$ & $C(23)-C(28)$ & $1.331(7)$ & 1.387 & 1.392 \\
\hline$C(3)-C(4)$ & $1.388(7)$ & $C(26)-C(27)$ & $1.381(6)$ & 1.398 & 1.398 \\
\hline$C(5)-C(6)$ & $1.363(6)$ & $\mathrm{C}(24)-\mathrm{C}(25)$ & $1.401(7)$ & 1.393 & 1.385 \\
\hline $\mathrm{C}(10)-\mathrm{C}(11)$ & $1.373(6)$ & $C(32)-C(37)$ & $1.369(6)$ & 1.405 & 1.404 \\
\hline $\mathrm{C}(16)-\mathrm{C}(17)$ & $1.375(6)$ & $\mathrm{C}(38)-\mathrm{C}(39)$ & $1.373(6)$ & 1.399 & 1.399 \\
\hline \multicolumn{6}{|l|}{ Bond angles $\left({ }^{\circ}\right)$} \\
\hline $\mathrm{N}(2)-\mathrm{N}(1)-\mathrm{C}(7)$ & $111.8(4)$ & $\mathrm{N}(4)-\mathrm{N}(3)-\mathrm{C}(29)$ & $112.4(4)$ & 112.72 & 112.67 \\
\hline $\mathrm{C}(9)-\mathrm{N}(2)-\mathrm{N}(1)$ & $110.1(4)$ & $\mathrm{C}(3 \mathrm{I})-\mathrm{N}(4)-\mathrm{N}(3)$ & $109.0(4)$ & 110.31 & 110.46 \\
\hline $\mathrm{C}(5)-\mathrm{C}(4)-\mathrm{C}(3)$ & $117.4(4)$ & $\mathrm{C}(25)-\mathrm{C}(26)-\mathrm{C}(27)$ & $117.8(4)$ & 118.83 & 116.80 \\
\hline $\mathrm{C}(6)-\mathrm{C}(1)-\mathrm{C}(2)$ & $122.7(5)$ & $C(28)-C(23)-C(24)$ & $124.5(5)$ & 121.92 & 119.89 \\
\hline$C(11)-C(10)-C(15)$ & $118.4(4)$ & $\mathrm{C}(37)-\mathrm{C}(32)-\mathrm{C}(33)$ & $117.8(5)$ & 118.81 & 118.62 \\
\hline $\mathrm{C}(17)-\mathrm{C}(16)-\mathrm{C}(21)$ & $116.8(4)$ & $\mathrm{C}(39)-\mathrm{C}(38)-\mathrm{C}(43)$ & $116.1(4)$ & 117.76 & 117.72 \\
\hline
\end{tabular}




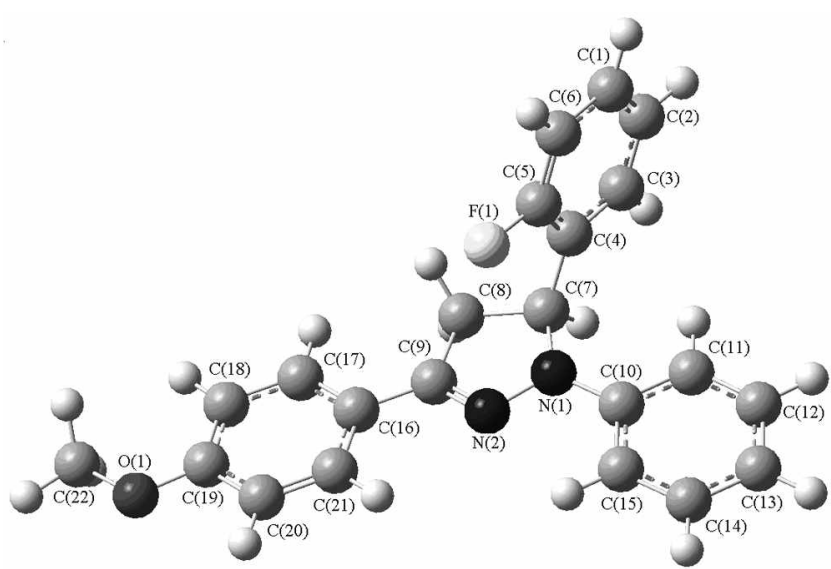

Figure 2. The optimized geometry for 2 with the same atomic scheme as 1 .

Optimized geometries. The optimized geometries of 1 and 2 have been obtained at B3LYP/6-31 $1 \mathrm{G}^{* *}$ level of theory. Although compound $\mathbf{1}$ contains two independent structural units in the solid state. the two molecules denote the same compound. So for $\mathbf{1}$ only one molecule is optimized and the optimized geometric parameters are also listed in Table 1 . The optimized structure of $\mathbf{2}$ is shown in Fig. 2. To make comparisons between compounds 1 and $\mathbf{2}$ more straightfonward. atomic numbering scheme was kept the same as in 1 . Even though there is no crystal stnicture of $\mathbf{2}$ available. the conformations of 2 and 1 are thought to be similar. So the optimized geometric parameters of 2 were compared with the values of the crystal structure of $\mathbf{1}$. The calculated geometric parameters of $\mathbf{2}$ are also included in Table 1 .

As seen in Table 1. most of the predicted geometric parameters have higher values than those determined experimentally. This is most likely due to the fact that the experimental data describe compound $\mathbf{1}$ in the solid state. whereas the calculated data correspond to the molecules in the gas phase. Comparing the predicted values with the experimental ones, it can be found that. for both compounds. the biggest difference in bond lengths is occurs at the $\mathrm{C}(23)-\mathrm{C}(28)$ bond with the difference being $0.056 \mathrm{~A}$ and $0.061 \mathrm{~A}$ for $\mathbf{1}$ and 2 . respectively: Considering the bond angles. the biggest variation between the experimental and predicted values is at bond angle of $\mathrm{C}(6)-\mathrm{C}(1)-\mathrm{C}(2)$ with the difference being $2.58^{\circ}$ for 1 and $4.61^{\circ}$ for 2 . Comparison between the calculated data of 1 with those of $\mathbf{2}$ indicates the differences between them are very small, with bond length difference being only $0.008 \AA$ at $\mathrm{C}(3)-\mathrm{C}(4)$ and bond angle difference being $2.03^{\circ}$ at bond angle of $\mathrm{C}(6)-\mathrm{C}(1)-\mathrm{C}(2)$. Aforementioned comparisons indicate that, the optimized geometry of 1 resembles closely its crystal structure and B3LYP/6-311G** level of theory can provide satisfying calculational precision for the system studied here. Although the position of fluorine atom in 2 is different from that in 1. the skeleton conformations of the two molecules are very similar. indicating that the position of fluorine atom in the molecules does not influence the geometries of $\mathbf{1}$ and $\mathbf{2}$ in a significant way:.

Atomic charge distributions. Based on the two optimized geometries. the NPA atomic distributions for $\mathbf{1}$ and $\mathbf{2}$ have
Table 2. NPA atomic charge distributions (e) and dipole moment (Debye) of 1 and 2

\begin{tabular}{ccc}
\hline group & 1 & 2 \\
\hline $\mathrm{N}(1)$ & -0.2617 & -0.2506 \\
$\mathrm{~N}(2)$ & -0.2629 & -0.2550 \\
$\mathrm{C}(7)$ & -0.0282 & -0.0294 \\
$\mathrm{C}(8)$ & -0.4295 & -0.4277 \\
$\mathrm{C}(9)$ & 0.2255 & 0.2264 \\
pyrazolinyl ring & -0.1133 & -0.0958 \\
1-position phenyl ring & 0.1066 & 0.0993 \\
3-position phenyl ring & 0.2147 & 0.2120 \\
$p^{\text {-inethosy }}$ & -0.2030 & -0.2052 \\
5-position phenyl ring & 0.3444 & 0.3371 \\
$\mathrm{~F}(1)$ & -0.3494 & -0.3474 \\
dipole moment & 4.1407 & 4.6423 \\
\hline
\end{tabular}

been calculated. The non-hydrogen atonic charges in pyrazolinyl ring and the total atonic charge distributions in pyrazolinyl ring and three aryl rings are listed in Table 2. The dipole moment values of $\mathbf{1}$ and $\mathbf{2}$ are also listed in Table 2 .

As seen in Table 2. introducing fluorine atom at different positions in 5-position phenyl ring of 2-pyrazolinyl ring has led to the atomic charge distributions in 1 and 2 being different. The fluorine atom in $\mathbf{1}$ is located at para position of 5-phenyl ring of 2-pyrazoline. which seens to make it has stronger electro-attracting ability than that in $\mathbf{2}$. where the fluorine atom is located at ortho-position of 5-phenyl ring of 2py razoline. For example. the atom $\mathrm{F}(\mathrm{l})$ in $\mathbf{1}$ has more negative charges $(-0.3494 e)$ than that in $2(-0.3474 e)$, while methoxy group in $\mathbf{1}$ has less negative charges $(-0.2030 \mathrm{e})$ than that in 2 $(-0.2052 e)$. Accordingly, three phenyl rings in 1 have more positive charges than the corresponding phenyl rings in $\mathbf{2}$ and the pyrazolinyl ring in $\mathbf{1}$ has more negative charges than that in 2. It is evident that such atomic charge redistributions have changed the positive-negative charges center and the dipole moment of $\mathbf{2}$ becomes bigger than that of $\mathbf{1}$ (see Table 2). It is postulated that the change in the atomic charge distribution influences the electronic and fluorescence spectra of $\mathbf{1}$ and $\mathbf{2}$ as discussed below:

Electınic spectia. For 1 and 2. experimental and theoretical electronic spectra are shown in Fig. 3 and the results are listed in Table 3. To compare the experimental spectra with theoretical values. TD-DFT method was applied to obtain a predicted electronic spectra based on the B $3 \mathrm{LYP} / 6-311 \mathrm{G}^{* * *}$ level optimized structures.

As seen in Fig. 3 and Table 3, in ethanol solution, both compounds $\mathbf{1}$ and $\mathbf{2}$ have three electronic transition bands and the locations of the three peaks are extremely near. but the intensities of the three peaks of $\mathbf{2}$ are lower than the corresponding peaks of $\mathbf{1}$. Theoretically. for $\mathbf{1}$ and $\mathbf{2}$. there are also three electronic transition bands obtained, but only two peaks of $\mathbf{2}$ are slightly weaker than those of $\mathbf{1}$. which is different from those in experiments. Compared the experimental data with the predicted ones, one can find other three differences between them: (1) all of the peak locations in theory have a few red shifts compared with those in experiment: (2) all of the theoretical peak intensities are stronger than the corres- 


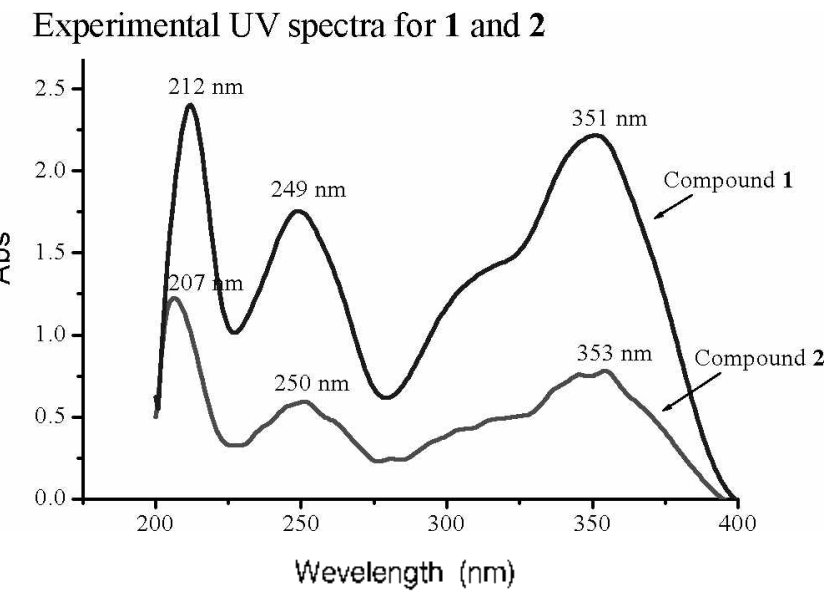

Theoretical UV spectra for $\mathbf{1}$ and $\mathbf{2}$

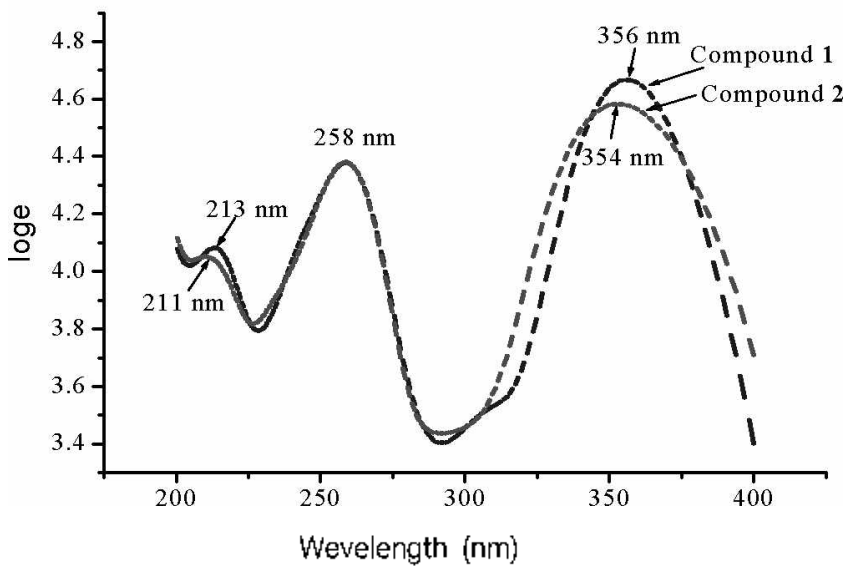

Figure 3. Experimental (top) and theoretical (bottom) electronic spectra for 1 and 2

Table 3. Experinental and theoretical electronic absorption spectra values

\begin{tabular}{|c|c|c|c|c|c|c|c|}
\hline \multicolumn{4}{|c|}{1} & \multicolumn{4}{|c|}{2} \\
\hline \multicolumn{2}{|c|}{ Exp. } & \multicolumn{2}{|c|}{$\begin{array}{c}\text { Calc. } \\
\text { (TD-DFT) }\end{array}$} & \multicolumn{2}{|c|}{ Exp. } & \multicolumn{2}{|c|}{$\begin{array}{c}\text { Calc. } \\
\text { (TD-DFT) }\end{array}$} \\
\hline $\begin{array}{c}\text { Have } \\
\text { leneth } \\
\text { (nin) }\end{array}$ & $\log \varepsilon$ & $\begin{array}{l}\text { waye } \\
\text { length } \\
\text { (nin) }\end{array}$ & $\log \varepsilon$ & $\begin{array}{l}\text { wave } \\
\text { length } \\
\text { (11i) }\end{array}$ & $\log \varepsilon$ & $\begin{array}{c}\text { wave } \\
\text { length } \\
\text { (nin) }\end{array}$ & $\log \varepsilon$ \\
\hline 212 & 3.68 & 213 & 4.08 & 206 & 3.38 & 211 & 4.05 \\
\hline 249 & 3.55 & 258 & 4.38 & 249 & 3.07 & 258 & 4.38 \\
\hline 351 & 3.65 & 356 & 4.67 & 353 & 3.19 & 354 & 4.58 \\
\hline
\end{tabular}

ponding ones in experiments: (3) in experiments. the weakest peak intensities are at about 249-259 rum. while in theory. the weakest peak intensities at about $211-213 \mathrm{~nm}$. Aforementioned comparisons suggest that for the system studied here. the B3LYP/6-311G** method simulates the electronic spectra with approximation. It is remarkable that the different substituted positions of fluorine atom in $\mathbf{1}$ and $\mathbf{2}$ do not change the locations of electron transition bands. but the electron transitions in $\mathbf{2}$ are more difficult than those in $\mathbf{1}$. which leads to the electron transition intensities of $\mathbf{2}$ being weaker than those of 1 . Natural population analyses based on the B3LYP/ $6-311 G^{* *}$ optimized geometries show that the frontier

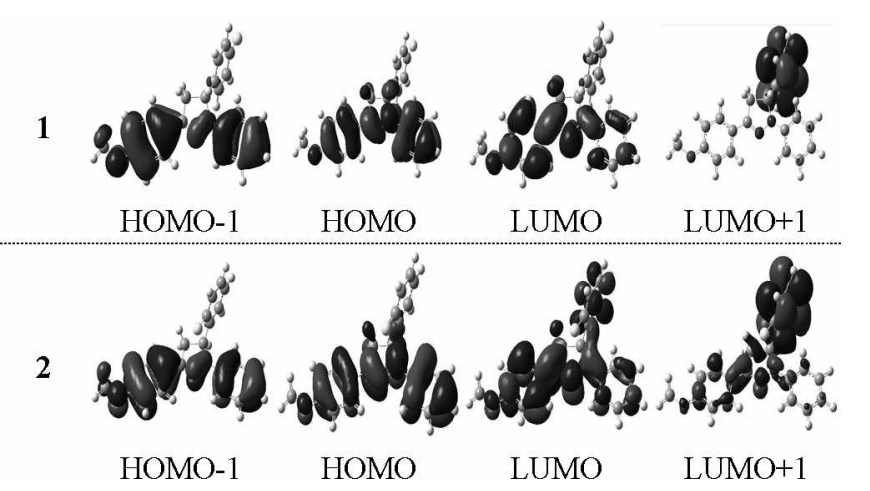

Figure 4. Surfaces of HOMO-1, HOMO, LUMO and LUMO+l for 1 and 2.

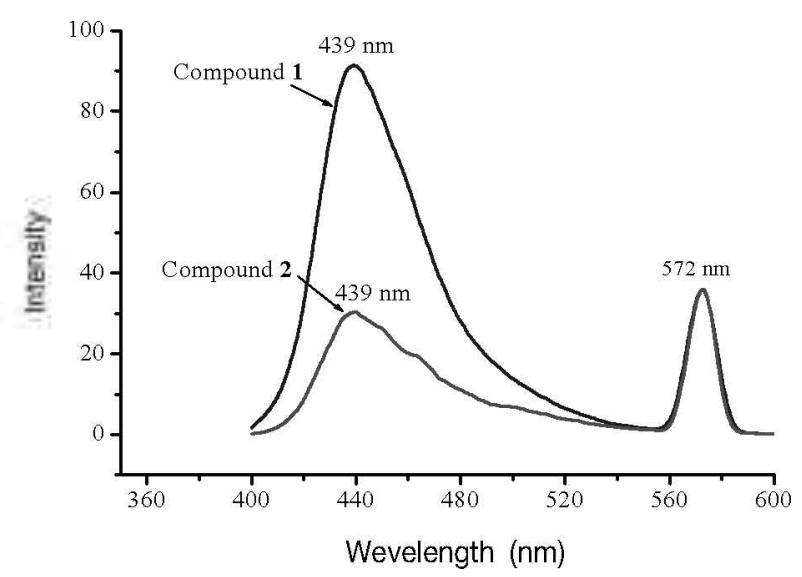

Figure 5. Experimental solid-state fluorescence emission spectra of 1 and 2.

molecular orbitals of $\mathbf{1}$ and $\mathbf{2}$ are mainly composed of $p$ atomic orbitals, so electronic transitions corresponding to above electronic spectra are mainly assigned to $n \rightarrow \pi^{*}$ and $\pi \rightarrow \pi^{*}$ electronic transitions. Fig. 4 shows the surfaces of the HOMO-1. HOMO, LUMO and LUMO +1 for 1 and 2. As seen in Fig. 4. for 1 and 2. the shapes of HOMO-l and HOMO are almost the same. while the shapes of LUMO and LUMO+l have some slight different.

In sum, although the different position of fluorine atom in 1 and 2 does not significantly change the electron transition models. it leads to different transition intensity in $\mathbf{1}$ and $\mathbf{2}$.

Fluorescence spectra. Experimental solid-state fluorescence spectra of $\mathbf{1}$ and $\mathbf{2}$ are shown in Fig. 5.

The emission bands of 1 and 2 are both observed at $439 \mathrm{~nm}$ and $572 \mathrm{~nm}$. lying in the blue-green region. At $439 \mathrm{~nm}$. the emission intensity of 2 is weaker than that of 1 and at $572 \mathrm{~nm}$. the emission intensities of $\mathbf{1}$ and $\mathbf{2}$ are the same. Evidently, fluorine atom located at $o$-position of 5-position phenyl ring of 2-pyrazoline in 2 decreases the fluorescence entission intensity compared with that of 1 . Maybe. this phenomenon is also resulting from the different atonic charge re-distributions in $\mathbf{1}$ and $\mathbf{2}$.

Themodynamic propenties. For 1 and 2. on the basis of vibrational analyses and statistical thermodynamics, the 
Table 4. Thennodynamic properties at different temperatures for 1 and 2

\begin{tabular}{|c|c|c|c|c|c|c|}
\hline \multirow{2}{*}{$\mathrm{T}(\mathrm{K})$} & \multicolumn{3}{|c|}{1} & \multicolumn{3}{|c|}{2} \\
\hline & $C^{0}{ }^{0} m\left(\mathrm{~J} \cdot \mathrm{m} m \mathrm{Ol}^{-1} \cdot \mathrm{K}^{-1}\right)$ & $S_{m}^{0}\left(\mathrm{I}^{\prime} \mathrm{mnol}^{-1} \cdot \mathrm{K}^{-1}\right)$ & $H_{m}^{0}\left(\mathrm{k} \cdot \mathrm{I}^{\mathrm{m}} \mathrm{mol}^{-1}\right)$ & $C_{p, m}^{0}\left(\mathrm{~J} \cdot \mathrm{mol}^{-1} \cdot \mathrm{K}^{-1}\right)$ & $S_{m}^{(1}\left(\mathrm{I} \cdot \mathrm{mol}^{-1} \cdot \mathrm{K}^{-1}\right)$ & $H_{m}^{\prime \prime}\left(\mathrm{k}^{\mathrm{T}} \cdot \mathrm{mol}^{-1}\right)$ \\
\hline 200.0 & 259.40 & 564.35 & 30.28 & 258.88 & 558.41 & 30.07 \\
\hline 298.1 & 379.73 & 690.17 & 61.60 & 379.19 & 684.02 & 61.34 \\
\hline 300.0 & 382.01 & 692.53 & 62.30 & 381.46 & 686.37 & 62.04 \\
\hline 400.0 & 498.32 & 818.73 & 106.45 & 497.77 & 812.41 & 106.13 \\
\hline 500.0 & 595.35 & 940.73 & 161.31 & 594.84 & 934.30 & 160.94 \\
\hline 600.0 & 672.85 & 1056.40 & 224.87 & 672.39 & 1049.87 & 224.45 \\
\hline 700.0 & 734.78 & 1164.94 & 295.36 & 734.38 & 1158.35 & 294.90 \\
\hline 800.0 & 785.01 & 1266.45 & 371.43 & 784.67 & 1259.81 & 370.94 \\
\hline
\end{tabular}

standard themodynamic functions: heat capacity $\left(C^{\prime)}{ }^{\prime}, m\right)$. entropy $\left(S_{m}^{\nu}\right)$ and enthalpy $\left(H_{m}^{\prime \prime}\right)$ were obtained and listed in Table 4 . The scale factor for frequencies is 0.96 . which is a typical factor for B3LYP/6-311G** method.

As observed in Table 4, all the values of $C_{p m}^{(1} s_{m}{ }_{m}$ and $H_{m}^{(i}$ increase with the increase of temperature from 100.0 to 800.0 $\mathrm{K}$. which is attributed to the enhancement of the molecular vibration while the temperature increases. Although 1 and 2 have the same atomic numbers and molecular weight. the substituted fluorine atom is at the different positions in $\mathbf{1}$ and 2. which results in the different vibrational models and frequencies and ultimately leads to the different thermody namic properties of 1 and 2 . As seen in Table 4, at each temperature, the thermody namic properties of $\mathbf{1}$ are slightly larger that those of 2

\section{Conclusions}

Two 2-pyrazoline derivatives of 1 and 2 have been synthesized and characterized by elemental analysis, IR, UV-Vis and fluorescence spectroscopy. The single crystal structure of 1 has been obtained. DFT calculations showed that the B3LYP/ $6-311 \mathrm{G}^{* *}$ level of theory can provide satisfactory precision in optimizing molecular geometries of 1 and 2. NPA atomic charge distributions analysis indicates that fluorine atom located at $p$-position of 5-position phenyl ring of 2-pyrazoline plays an important role in pulling the electrons from the other part of the molecule to $F(1)$ atom. which leads to the redistributions of the atomic charge in 2 being different from those in 1 . All of the predicted electronic transition bands for $\mathbf{1}$ and $\mathbf{2}$ have a few red-shifts as compared to the experimental values and all the theoretical peak intensities are stronger than those of experimental ones. When the experimental electronic and fluorescence spectra were considered. it was apparent that the different position substitution of fluorine atom in the 5-phenyl ring of the pyrazoline changed the peak intensity. Knowing how the substitution in the 5-phenyl ring of the pyrazoline affects the compound's spectroscopic properties may be a useful tool in studying pyrazoline-based electroluminescent materials.

Supplementary Data Cry stallographic data for the stnicture reported here have been deposited with Cambridge Crystallographic Data Center (Deposition No. CCDC-700789). The data can be obtained free of charge via www.ccdc.cam.ac.uk/ conts/retrieving.html (or from the CCDC. 12 Union Road, Cambridge CB2 IEZ, UK: fax: +4+ 1223 336033: e-mail: depositaccdc.cam.ac.uk).

Acknowledgments. This work was supported by Natural Science Foundation of Shandong Province (No. Y2008B29. Y2007B 14. Y2006B08). P. R. China. Doctoral Fund of Shandong Province. P. R. China. (No.2006BS01043) and Doctoral Fund of Qingdao University of Science \& Technology.

\section{References}

1. Salbeck, J.: Yu, N.; Baner, J.; Weissortel, F,; Bestgen, H. Synth. het 1997, 91, 209-215.

2. Grice, A. W.: Tajbakhsh, A.: Bur, P. L.: Bradley, D. D. C. Adv. Nater. 1997, 9, 1174-1178.

3. Gao, Z. Q.; Lee, C. S.; Bello, I.; Lee, S. T.; Chen, R. M.; Lu, T. Y. Appl. Phys. Lett. 1999, 74, 865-868

4. Yan, Z. L.; Hu, G. W.: Wu, S. K. Acta Chim. Sin. 1995, 53. 227-229.

5. Wagner, A.; Schellhammer, C. W.; Petersen, S. Angew. Chem. Int. Ed. Engl. 1966, 5, 699-704.

6. Dorlars, H.; Schellhammer, C. W.; Schroeder, J. Angew. Chem. Int. Ed. Engl. 1975, 14,665-679.

7. Sarkar, A. K. Flnorescent whitening agents, Watford: England, Merrow, 1971

8. Ji, S. T.: Shi, H. B. Dves. Pigntents. 2006, 70, 246-250

9. Yang, G. B.; Wu, Y.; Tian, W. J.; Zhou, X,; Ren, A. M. Curr. 4ppl. Phus. 2005, 5, 327-330.

10. Lu, Z. Y.; Jiang, Q.: Zhu, W. G.: Xie, M. G.: Hou, Y. B.: Chen, X. H.: Wang, Z. J.: Zou, D. C. T. Tsutsui, Sinthetic het. 2000. $111-112,425-427$.

11. Wang, M. L.; Zhang, J. X; Liu, J. Z.; Xu, C. X.; Ju, H. X. J. Lumin. 2002, 99, 79-83.

12. Zhao, P. S.; Li, Y. F.; Guo, H. M.: Jian, F. F.; Wang, X. Bull. Korean Chem. Soc. 2007, 28, 1539-1544.

13. Zhao, P. S.; Li, Y. F.; Guo, H. M.; Wang, X.; Jian, F. F. Polish J. Chent 2007,81, 1735-1742.

14. Jian, F. F.; Zhao, P. S.; Guo, H. M.; Li, Y. F. Spectrochimt Acto $12008,69,647-653$

15. Zhao, P. S.: Wang, H. Y.: Li, R. Q.; Gno, H. M. Indian J. Chem. A 2008, $47,986-991$

16. Guo, H. M.; Tian, F. F.; Zhao, P. S.; Zhang, Y. C.; Li, Y. F. Acto Const. 2007, E63, 0215-0216.

17. Sheldrick, G. M. SHELITL, y Reference Mamat: Siemens Analytical X-Ray Systems: Madison, WI, 1997.

18. Wilson, A. I. Intemational Table for X-Ran Cnstallography, Kluwer Academic: Dordrecht, The Netherlands, 1992; Vol. C, Tables 6.1.1.4, pp 500-502 and 4.2.6.8, pp 219-222. 
19. Dewar, M. J. S.; Zoebisch, E. G.: Healy, E. F.; Stewart, J. J. P. J. Am. Chem. Soc. 1985, 107, 3902-3909.

20. Peng, C.: Ayala, P. Y.: Schlegel, H. B.: Frisch, M. J. J. Comput. Chem. 1996, 17, 49-56.

21. Frisch, M. T.; Trucks, G. W: Schlegel, H. B.; Scuseria, G. E.; Robb, M. A.; Cheeseman, J. R.; Montgomery, J. A.; Vreven, Ir., T.: Kudin, K. N.: Burant, I. C.: Millam, J. M.; Iyengar, S. S.: Tomasi, J.; Barone, V:- Mennucci, B.: Cossi, M.: Scalmani, G.; Rega, N.; Petersson, G. A.; Nakatsuli, H.; Hada, M.; Ehara, M.; Toyota, K.; Fukuda, R.: Hasegawa, J.: Ishida, M.; Nakajima, T.: Honda, Y.: Kitao, O: Nakai, H.: Klene, M: Li, X.: Knos, I. E.: Hratchian, H. P. Cross, J. B.; Adamo, C. Taramillo, T; Gomperts, R: Stratmann, R. E.; Yazyev, O.: Austin, A. T.: Cammi, R.; Ponelli, C.; Ochterski, I. W. Ayala, P. Y: Morokmma, K.; Voth, G. A.: Salvador, P: Dannenberg, J. J.: Zakrzewski, V. G.: Dapprich, S.; Daniels, A. D.: Strain, M. C.; Farkas, O : Malick,
D. K.: Rabuck, A. D.: Raghavachari, K.; Foresman, J. B.: Ortiz, I. V; Cui, Q; Baboul, A. G.: Clifford, S.: Cioslowski, T.; Stefanov, B. B.: Lill, G.; Liashenko, A.; Piskorz, P.; Komaromi, I.; Martin, R. L.; Fox, D. T.; Keith, T; Al-Laham, M. A.; Peng, C. Y.; Nanayakkara, A.; Challacombe, M.; Gill, P. M. W.; Johnson, B.; Chen, W. Wong, M. W. Gonzalez, C.: Pople, I. A Gaussian, Inc., Gaussian 03, Revision C.01: Wallingford. CT, 2004.

22. Runge, E.; Gross, E. K. U. Phws. Rev Lett. 1984, 52, 997-1000.

23. Petersilka, M; Gossmann, U. T; Gross, E. K. U. Phys. Rew Lett. 1966, 76, 1212-1215.

24. Banernschmitt, R.; Ahlrichs, R. Chem. Phys. Let. 1996, 256. $454-464$.

25. Jamorski, C.; Casida, M. E.; Salahub, D. R. J. Chem. Phys. 1996, $104,5134-5138$.

26. Fahrni, C. I.; Yang, L. C.: VanDerveer, D. G. J. Am. Chem. Soc. $2003,125,3799-3812$. 